\title{
Thermal preference, tolerance and temperature-dependent respiration in the California sea hare Aplysia californica
}

\author{
Ana Denisse $\operatorname{Re}^{1^{*}}$, Fernando Díaz ${ }^{1}$, Alfredo Salas-Garza ${ }^{2}$, Marco Gonzalez ${ }^{2}$, Victor Cordero ${ }^{1}$, \\ Clara E. Galindo-Sanchez ${ }^{3}$, Edna Sanchez-Castrejon ${ }^{4}$, Adolfo Sánchez Zamora ${ }^{5}$, \\ Alexei Licea-Navarro ${ }^{1}$

\footnotetext{
${ }^{1}$ Laboratorio de Ecofisiología de Organismos Acuáticos, Departamento de Biotecnología Marina, Centro de Investigación Científica y de Educación Superior de Ensenada (CICESE), Ensenada Baja California, México; ${ }^{*}$ Corresponding Author: denisre@cicese.mx

${ }^{2}$ Instituto de Investigaciones Oceanológicas, Universidad Autónoma de Baja California, Ensenada Baja California, México

${ }^{3}$ Laboratorio de Genómica Funcional, Departamento de Biotecnología Marina, Centro de Investigación Científica y de Educación Superior de Ensenada (CICESE), Ensenada Baja California, México

${ }^{4}$ Laboratorio de Biología Celular y Molecular, Departamento de Biotecnología Marina, Centro de Investigación Científica y de Educación Superior de Ensenada (CICESE), Ensenada Baja California, México

${ }^{5}$ Unidad Multidisciplinaria de Docencia e Investigación, Facultad de Ciencias, Universidad Autónoma de México, Sisal, México
}

Received 20 April 2013; revised 20 May 2013; accepted 10 June 2013

Copyright (C) 2013 Ana Denisse Re et al. This is an open access article distributed under the Creative Commons Attribution License, which permits unrestricted use, distribution, and reproduction in any medium, provided the original work is properly cited.

\begin{abstract}
The thermoregulatory behavior of sea hare Aplysia californica was determined in a horizontal thermal gradient; with a preferred temperature (PT) of $18.3^{\circ} \mathrm{C}$ for the day cycle and $20.8^{\circ} \mathrm{C}$ for the night cycle. The displacement velocity demonstrated an initial rate of $30 \mathrm{~cm} \cdot \mathrm{h}^{-1}$ and gradually the velocity diminished to $18 \mathrm{~cm} \cdot \mathrm{h}^{-1}$ with several fluctuations mainly at 02:00 am. Critical Temperature Maxima (СTMax refers to the temperature point where at least $50 \%$ of the experimental group have a loss of attachment) was measured at three acclimation temperatures $\left(16^{\circ} \mathrm{C}, 19^{\circ} \mathrm{C}\right.$ and $\left.22^{\circ} \mathrm{C}\right)$. At the lowest acclimation temperature $\left(16^{\circ} \mathrm{C}\right), 50 \%$ of the experimental group had an attachment loss at CTMax $32.7^{\circ} \mathrm{C}$, and in a higher acclimation temperature $\left(22^{\circ} \mathrm{C}\right) \mathrm{CTMax}$ was $36.2^{\circ} \mathrm{C}$. The Oxygen Consumption Rate (OCR) was closely correlated to acclimation temperature, and at $16^{\circ} \mathrm{C}$ and $19^{\circ} \mathrm{C}$ sea hare had a relatively stable metabolic rate, with OCR increasing to $9 \mathrm{mg} \mathrm{O}_{2}$ $\mathrm{h}^{-1} \cdot \mathrm{kg}^{-1} \mathbf{w} . \mathrm{w}$. in a higher acclimation temperature.
\end{abstract}

Keywords: Thermoregulatory Behavior; CTMax; Oxygen Consumption; Aplysia californica

\section{INTRODUCTION}

In the case of ectothermic organisms the growth rate is temperature-dependent. Several laboratory studies of $A$. californica have documented these rates at different rearing temperatures. It has been a standard hatchery practice to maintain a post-metamorphosis rearing temperature of $15^{\circ} \mathrm{C}$, with the objective to prevent the onset of sexual maturity before 9 months of age [1-4].

Recently, environmental factors involving influence on growth of A. californica have been studied in laboratoryreared under controlled conditions [5]. The decision to analyze Aplysia's behavior in this particular ambiance has its logic in the similar conduct Aplysia expresses in the field or in a regulated context. Nonetheless, there are differences caused by the greater environmental factors in the field compared to laboratory environments [6].

Aplysia californica is found between Oregon and the Gulf of California, and Aplysia vaccaria is extended from California to the Gulf of California [7]. [8] found only one specimen of Aplysia californica in Las Conchas Ecuador. $[3,4,9]$ varied on the following factors such as temperature, food or stocking density in A. californica, maintained in laboratory conditions, while keeping the others constant; these studies demonstrated that each factor had a strong effect on growth rate and size at sexual maturity. One factor that does not appear to influence growth and maturation, however, is the time of year the life cycle begins $[2,10,11]$.

[5] correlated that rearing temperatures would influence the growth rate and longevity at which A. californica becomes sexually mature in the laboratory. They observed that A. californica lives more days in low tem- 
peratures than higher, but the size is larger in high temperatures. Probably there are multiple effects in its metabolism, unfortunately there is not enough information in order to know them or to determine which would be its best performance at a given temperature.

Behavioral thermoregulation can be adaptive in two complementary ways: 1) it can help an organism avoid extreme heat or cold that could be damaging or lethal [12]; 2) it can increase the time an animal spending at optimal physiological temperatures [13]. The thermal preference of a species corresponds closely with a temperature that maximizes growth, and other physiological processes $[14,15]$. The temperature intervals in which the organism congregates or spends time are defined operationally as preferred temperature or thermal preference [16]. In order to determine these two processes two methods are utilized, acute and gravitational by bipartite definition [17]. As for the gravitational method it takes 24 hours and the preferendum to determine organisms gravitates freely towards their preferred temperature [18, 19].

[20] mentions that critical thermal limits are typically determined experimentally within a controlled laboratory environment and are often based on dynamic non-lethal or static lethal methods. The Critical Thermal Method involves a dynamic changing temperature at a constant rate until a Critical Thermal End Point (predefined sublethal endpoint), is reached. In order to measure thermal tolerance in marine environment, where organisms are often exposed to relatively high temperatures, the CTMax previously mentioned is likely to be one of the principal methods in terms of ecological significance [21].

Thermal stress in aquatic organisms is likely to increase with the effect of global climate change. CTE is a behavioral stress response and is defined as the arithmetic mean of collecting thermal points at which mobile activity becomes disorganized to the point that organisms lose their ability to escape conditions that will lead to death [22]. The analogous behavioral stress response of aquatic macroinvertebrates varies amongst taxa but generally includes inability to remain attached to a substrate or increased movement, followed by immobility with a lack of response when stimulated [23].

In the intertidal zone, organisms can spend part of their lives immersed in stable and benign seawater and the remaining time in extreme conditions during emersion. Therefore, the relationship between temperature and metabolism of animals living in the intertidal zone can provide a suitable model to clarify their physiological adaptation to temperature fluctuation [24]. Among the physiological parameters that correlate with environmental changes such as temperature, the measurement of the metabolic rate allows us to determine the energetic cost that combinations have on an organism [25-27]. According to $[28,29]$ the oxygen consumption rate $(O C R)$ is intimately associated with metabolic work and the energy flow that an organism can use for homeostatic control mechanisms.

The aim of this study is to know in Aplysia californica, the preferred temperature in which it can be correlated to the optimal growth, the effect of critical temperature in order to know its thermal tolerance, and in which temperature it has its best metabolic response.

\section{MATERIALS AND METHODS Sea Hare and Experimental Design}

Adult Aplysia californica were collected in nets in the intertidal zone in the area of Punta Morro Baja California, México (32.25 Lat N 116.983 Long W). The organisms were kept for thirty days in reservoirs of $2000 \mathrm{~L}, 35 \%$ salinity and $16^{\circ} \mathrm{C} \pm 1{ }^{\circ} \mathrm{C}$ as the same conditions measure in the moment of capture in a flow-through water system. The photoperiod was maintained at 12 - $12 \mathrm{~h}$ light-dark with a 30 minute transition periods in between.

We used 90 organisms acclimated to $16^{\circ} \mathrm{C}, 19^{\circ} \mathrm{C}$ and $22^{\circ} \mathrm{C} \pm 1{ }^{\circ} \mathrm{C}$ experimental condition. The Aplysia californica was kept for 21 days in acclimated time. Afterwards, a group of 6 organisms was introduced to the horizontal thermal gradient described by [30]. A Neslab thermoregulator (HX model 150) was connected at one end to cool the water gradient. A 1000 watts heater was placed at the opposite end connected to a temperature controller (Moeller CI-K3-125-M), generating a steady gradient of $10^{\circ} \mathrm{C}$ to $30^{\circ} \mathrm{C},\left(\mathrm{y}=6.20+1.60 \mathrm{x}, \mathrm{r}^{2}=0.98\right.$ where $\mathrm{x}=$ gradient segments, and each segment $=$ temperature gradient). Twenty aeration stones were placed along the gradient to maintain a dissolved oxygen concentration of 5.8 $-7.2 \mathrm{mg} \cdot \mathrm{L}^{-1}$ and thus eliminate the effect of stratification of the water column. The depth of the water column in the gradient was $9 \mathrm{~cm}$ and to maintain good water quality turnover rate was $10.0-12.0 \mathrm{~L} \cdot \mathrm{h}^{-1}$. Every organism was tagged with a nylon tread, a circular plastic tag allowed us to identify the experimental organism behavior; now we could determine the preferred temperature gravitational method as applied and described by [18].

Six tagged Aplysia were introduced to the gradient in the segment where the water temperature was the same as that of the experimental acclimation temperatures. They were exposed at day to a light intensity of $0.55 \times$ $10^{15}$ quanta $\cdot \mathrm{sec}^{-1} \cdot \mathrm{cm}^{-2}$ and at night to a light intensity of $0.09 \times 10^{15}$ quanta $\cdot \mathrm{sec}^{-1} \cdot \mathrm{cm}^{-2}$. For each temperature there were four trials performed $(\mathrm{N}=60)$. Nudibranches were not fed $24 \mathrm{~h}$ before the trial period to avoid interference from the diet $[31,32]$.

The velocity displacement of the sea hare in the gradient was determined by observing the tagged organism in each segment of the trough every hour during the $24 \mathrm{~h}$ period, expressed in $\mathrm{cm} \cdot \mathrm{h}^{-1}$. A Mann-Whitney test was used to determine the differences in preferred tempera- 
ture and the displacement velocity of sea hare in the light and dark cycle [33]. Temperature preference data was processed with Exploratory Data Analysis [34] and plotted as parallel boxes.

To determine the Critical Thermal Maxima (CTMax), 45 sea hare were acclimated in three $2000 \mathrm{~L}$ tanks at temperatures of $16^{\circ} \mathrm{C}, 19^{\circ} \mathrm{C}$ and $22^{\circ} \mathrm{C} \pm 1{ }^{\circ} \mathrm{C}$, and a salinity of $35 \%$, for 21 days to allow acclimation to experimental temperatures. Twenty four hours before trials initiated the sea hare were not fed. The organisms were placed on acrylic plates $(30 \times 25 \times 0.4 \mathrm{~cm})$ and left undisturbed overnight; the acrylic plates were suspended 12 $\mathrm{h}$ in $40 \mathrm{~L}$ glass aquarium with aeration. Each aquarium was thermostatically controlled with a $1000 \mathrm{~W}$ heater and an air stone $(15 \times 5 \times 5 \mathrm{~cm})$. The temperature was raised from the acclimation temperatures of $16^{\circ} \mathrm{C}, 19^{\circ} \mathrm{C}$ and $22^{\circ} \mathrm{C} \pm 1{ }^{\circ} \mathrm{C}$ at a rate of $1^{\circ} \mathrm{C}$ every 15 minutes $[30,35,36]$.

Determinations of CTMax of the sea hare responses were made between 10:00 and 13:00 h. visual monitoring was performed and recorded the time and temperature at which they showed a curled mantle and started to lose attachment, the organisms immediately were transferred into acclimation tanks for recovery. The organisms were used only once. The data from sea hare that did not recover after returning to acclimation temperatures was discarded. The Kruskall-Wallis test was used to determine differences between groups [33]. The temperature, at which 50\% remain attached, was calculated using linear regression, previous transformation to arcsine SigmaStat, version 3.1 (Systat Software Inc., San Jose, CA) on all points below $100 \%$.

Oxygen consumption was measured in a semi open system, 15 organisms from each acclimation temperature were placed individually in a $1.0 \mathrm{~L}$ Erlenmeyer flask. Sea hare were placed in the respirometric system $24 \mathrm{~h}$ before the beginning of the measurements in order to allow their acclimation to the system. The dissolved oxygen in the Erlenmeyer flasks was measured with an YSI 52 oxymeter equipped with a polarographic sensor; organisms were maintained without food for $24 \mathrm{~h}$. A water sample was taken to measure the initial concentration of dissolved oxygen, the water flow in the Erlenmeyer flasks were kept closed for an hour, since according to [37] this time is sufficient to avoid the dissolved oxygen decrease to below $30 \%$ not causing stress in the organisms. At the end, new water samples were taken from each Erlenmeyer flask to measure the final concentration of dissolved oxygen. The difference between the initial and final gas concentration was the oxygen consumed by the organisms expressed in $m g \mathrm{O}_{2} \mathrm{~h}^{-1} \cdot \mathrm{g}^{-1}$ d.w. The oxygen consumption rate $(O C R)$ was calculated according to Equation (1) [38,39].

$$
\text { OCR }=\left(C_{t}-C_{0}\right) V /(W \times T)
$$

where $C_{t}$ is the change in the oxygen content in the respirometric chambers before and after the test; $C_{0}$, is the change of the oxygen content in the blank (control); $V$ is the volume of the chamber; and $W$ and $T$ are the wet sea hare biomass in $\mathrm{kg}$ and the time duration in hours, respectively. During the experimental phase, a control Erlenmeyer flask was maintained without organisms in order to measure the oxygen consumption and ammonium production of the microorganisms present in the respirometric system, where necessary corrections were made. The Kruskall-Wallis test was used to determine differences between groups [33].

\section{RESULT AND DISCUSSION}

The thermoregulatory behavior of sea hare Aplysia californica was determined in a horizontal thermal gradient, $18.3^{\circ} \mathrm{C}$ for the day cycle and the $20.8^{\circ} \mathrm{C}$ for the night cycle (Figure 1); the organisms were never found below $11^{\circ} \mathrm{C}$ or above $31.0^{\circ} \mathrm{C}$ in trough temperatures. There was a significant difference in preferred temperatures of sea hare between day and night cycles $(\mathrm{P}<0.05)$. [40] also found a diel rhythm in the freshwater gastropod Helisoma trivolis, which had a preferred temperature of $21^{\circ} \mathrm{C}-22^{\circ} \mathrm{C}$ during night cycle and $17^{\circ} \mathrm{C}-18^{\circ} \mathrm{C}$ during day cycle. [36] obtained in (Megastrea Lithopoma) undosa an interval of preferred temperature of $16.2^{\circ} \mathrm{C}$ in the day cycle and $14.4^{\circ} \mathrm{C}$ in night cycle.

Diel differences in preferred temperatures between day and night cycles have been observed in other aquatic ectotherms, including Amia calva [16], Procambarus

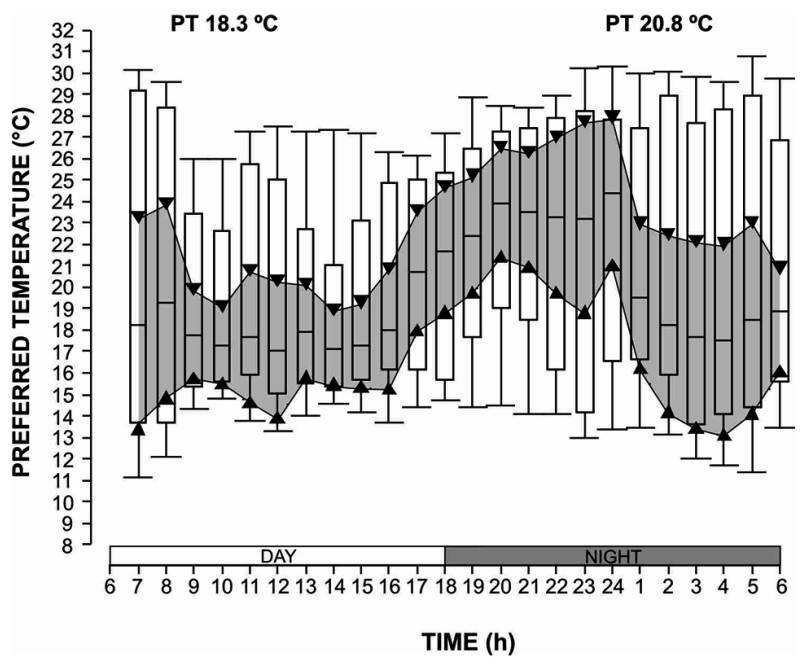

Figure 1. Thermoregulatory behaviour of adults of Aplysia californica in a day-night cycle. The shadow zone bordered by triangles represents the $95 \%$ confidence interval of the median. The bars include $50 \%$ of the distribution and the vertical lines represent the quartiles. 
spiculifer [41,42], and Procambarus clarkii. According to [43] this behavior may be explained with the bioenergetics hypothesis, suggesting that diel changes in preferred temperatures may reflect differences in the temperatures favorable for feeding versus temperatures favorable when food is limited. In adults $A$. californica the diel thermoregulatory behavior obtained indicates that in the habitat of sea hare the food is a limiting factor.

This study concludes that the selection of A. californica of these specific preferred temperatures, which has a correlation with its optimum growth rate and sexual maturity. [5] observed that at 205 days of age the fastest growth rates occurred between $18^{\circ} \mathrm{C}$ and $21^{\circ} \mathrm{C}$, and animals reared in the same thermal interval reached sexual maturity at ages 190 to 197 days.

The displacement velocity of sea hare in the gradient showed an initial velocity of $30 \mathrm{~cm}$ by hour and gradually diminished to $18 \mathrm{~cm}$ per hour, with several fluctuations. We can see a small effect at 18 hours (moment of transition from day to night); the displacement velocity had a very slow activity $<5 \mathrm{~cm}$ per hour, with an increasing activity at 2:00 a.m. (Figure 2). According to [44], sea hare used an orthothermokinesis orientation mechanism, because it offered the greatest scope of activity [17]. Thus, sea hare remains within a relatively narrow temperature range, decreasing the displacement velocity to $18.0 \mathrm{~cm} \cdot \mathrm{h}^{-1}$. [6] observed A. californica in the intertidal zone, where they moved over a distance of 10 $\mathrm{m}$ or more per day. This behaviour is correlated with the displacement velocity observed in the horizontal thermal gradient during the diel cycle.

CTMax was evaluated at three temperatures $\left(16^{\circ} \mathrm{C}\right.$, $19^{\circ} \mathrm{C}, 22^{\circ} \mathrm{C}$ ), and we observed attachment percentages changed in relation to the acclimated temperature (Figure 3). For A. californica the relationship between percentage of attached organisms on the plate and acclimation temperature is represented as follows.

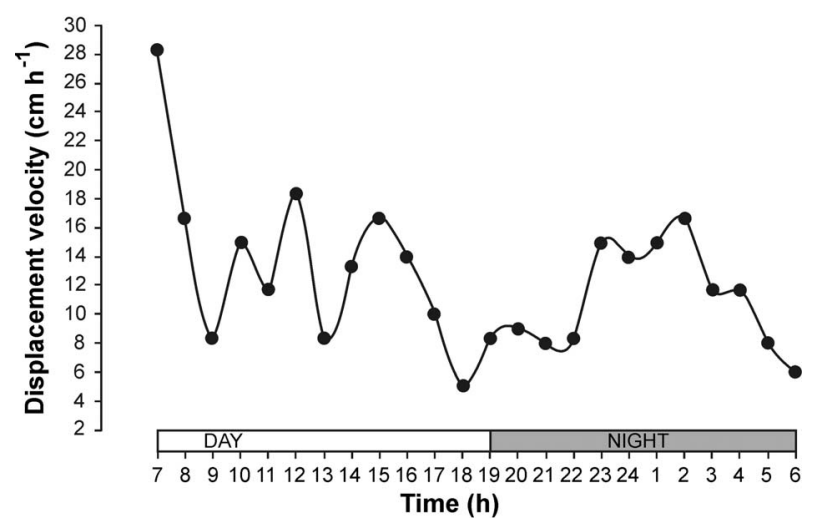

Figure 2. Displacement velocity of sea hare Aplysia californica in a horizontal thermal gradient, in a day night cycle.
For organisms acclimated to $16^{\circ} \mathrm{C}$ this equation was:

$$
y=34.92-0.0362 x \text { with a }{ }^{2}=0.90
$$

For acclimated sea hare to $19^{\circ} \mathrm{C}$ this relationship was:

$$
y=36.16-0.039 x \text { with a } r^{2}=0.98
$$

As for sea hare acclimated to $22^{\circ} \mathrm{C}$ this relationship was:

$$
y=38.35-0.038 x \text { with } \text { a }^{2}=0.89
$$

$16^{\circ} \mathrm{C}$
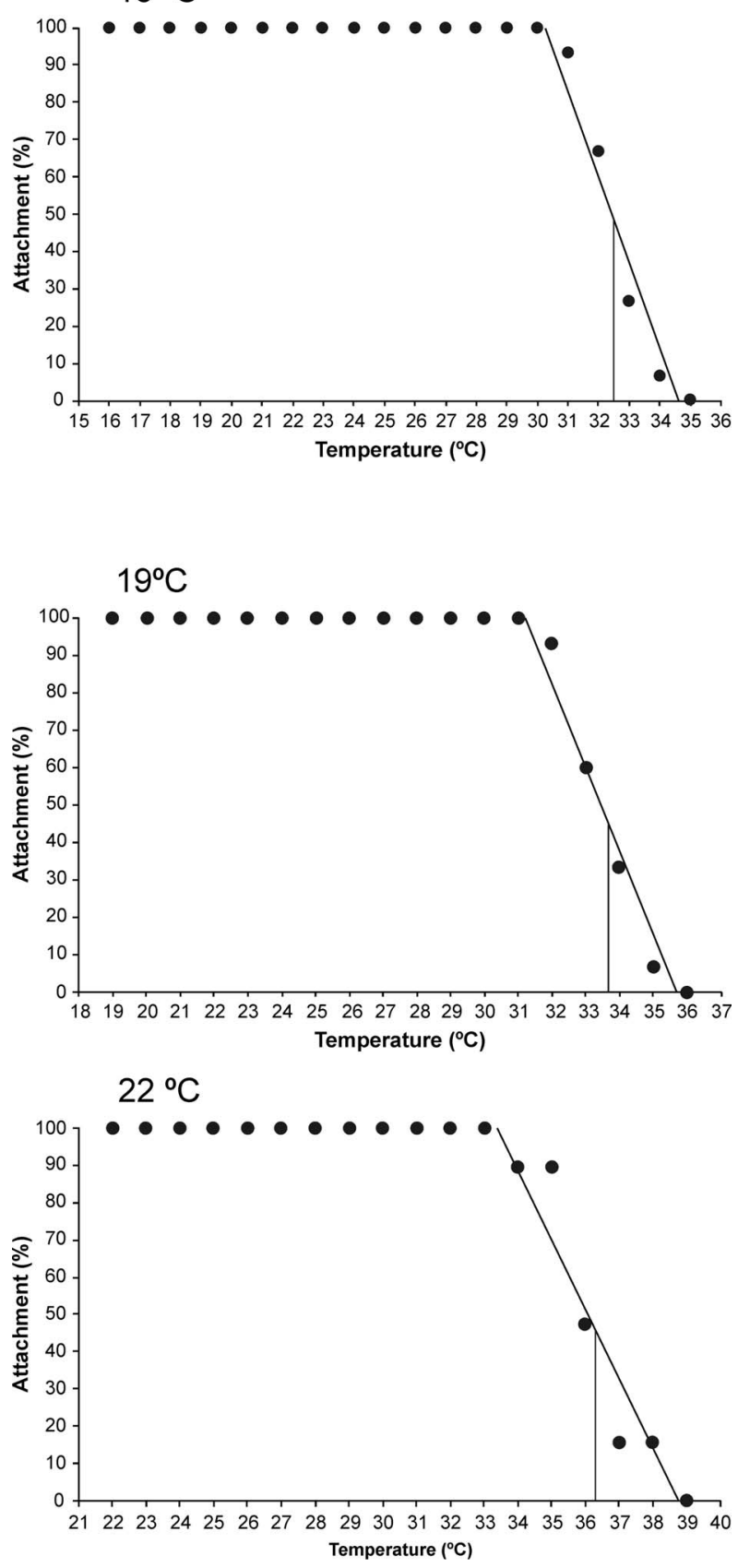

Figure 3. Percentage of sea hare Aplysia californica remaining attached plotted against different acclimation temperatures. The continuous line denotes the critical thermal maxima at 50\%. 
where $y=$ temperature and $x$ percentage of attached organisms. For sea hare acclimated at $16^{\circ} \mathrm{C}$, the last organism to lose holding was registered at $31^{\circ} \mathrm{C}$. In the case of the animals who were maintained at $22^{\circ} \mathrm{C}$, the sea hare that ultimately had a loss of attachment reaching a temperature of $39^{\circ} \mathrm{C}$ (Figure 3). As for the CTMax (defined by the moment where $50 \%$ of the sea hare remained attached), the temperatures were $32.7^{\circ} \mathrm{C}, 33.6^{\circ} \mathrm{C}$ and $36.2^{\circ} \mathrm{C}$ to $16^{\circ} \mathrm{C}, 19^{\circ} \mathrm{C}$ and $22^{\circ} \mathrm{C}$ acclimated temperatures respectively (Figure 3). After the exposure to determine CTMax, organisms were returned to their acclimation temperature for $96 \mathrm{~h}$, and they had a $98 \%$ survival rate.

In this study, the CTMax of Aplysia californica was determined by a methodology that involves dynamic changes in temperature. [30] presented a summary of the critical thermal maxima at $50 \%$ for various species of gastropods of genus Haliotis, acclimated to different temperatures and salinities. In the determination of CTMax to $50 \%$, sea hare was subjected to a continuous and constant linear increase in temperature until an endpoint was reached; when we changed acclimation temperatures from $16^{\circ} \mathrm{C}$ to $19^{\circ} \mathrm{C}$, we observed an attachment increase of $3 \%$, and from $16^{\circ} \mathrm{C}$ to $22^{\circ} \mathrm{C}$, thermal tolerance increased in $10 \%$.

When Aplysia went through the process of reaching the end point of CTMax it had several particular responses. It maintained the mantle spread and stacked it to the acrylic plate during the first minutes, later the mantle looked deployed and well spread. When sea hare was about to arrive to the ending point, its mantle started to curl causing the body to rise and looked like a balloon. Finally at the point of losing attachment its mantle displayed many ruffles, this process continued to intensify until the mantle had a complete loss of adhesion; the endpoint of CTMax is marked when Aplysia starts to float.

According to $[45,46]$ the attachment capacity in marine gastropods is the result from the sum of two main components: the proteinaceous or mucopolysaccharide secretions and the muscular activity that maintains the suction force from the foot and its shape. It also has been shown that temperature affects the capacity of attachment of different species such as sea urchins, abalones, sea cucumbers, and wavy turban snail [30,36,47-49].

Oxygen consumption rate $(O C R)$ in A. californica was closely related to acclimation temperature. At $16^{\circ} \mathrm{C}$ and $19^{\circ} \mathrm{C}$ sea hare had a relatively stable metabolic rate with a slight variation between 5 to $6 \mathrm{mg} \mathrm{O} \cdot \mathrm{h}^{-1} \cdot \mathrm{kg}^{-1}$ w.w., and when acclimation temperature increased from $19^{\circ} \mathrm{C}$ to $22^{\circ} \mathrm{C}$, OCR increased to $9 \mathrm{mg} \mathrm{O}{ }_{2} \cdot \mathrm{h}^{-1} \cdot \mathrm{kg}^{-1}$ w.w. (Figure 4). Once the sea hare was in a temperature of $22^{\circ} \mathrm{C}$ there was an increase of $150 \%$ of oxygen consumption rate, indicating the high need of oxygen supply requirements. In the case of sea cucumber, Apostichopus japonicus, when exposed to higher temperatures [24] it

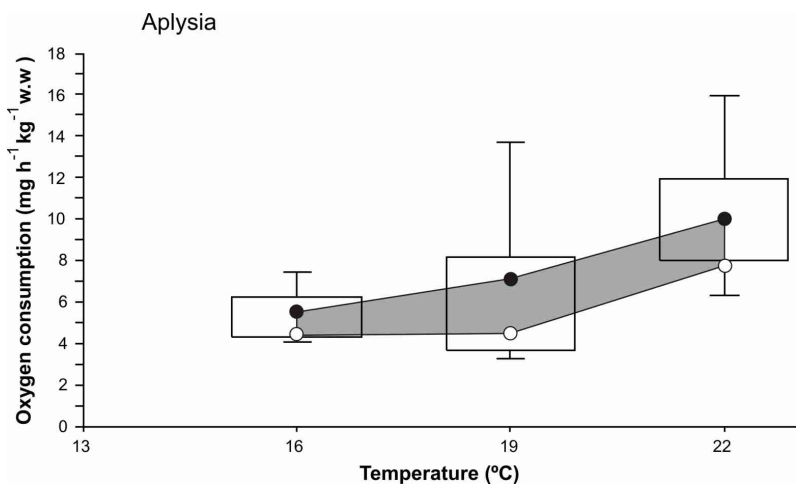

Figure 4. Oxygen consumption rate of sea hare Aplysia californica acclimated at different temperatures. The shadow zone bordered by circles represents the $95 \%$ confidence interval of the median. The bars include $50 \%$ of the distribution and the vertical lines represent the quartiles.

obtained a similar response in OCR; according to [24,50] this pattern suggests that high thermal tolerance may come with a significant fitness and energetic cost. In low temperatures $\left(16^{\circ} \mathrm{C}\right.$ to $\left.19^{\circ} \mathrm{C}\right)$ Aplysia californica reduced their oxygen consumption and had an increment on physiologically useful energy, enhanced food conversion, and favored the saving of metabolic energy that can be used for growth, eating or reproduction activities [5].

\section{ACKNOWLEDGEMENTS}

We thank Jose M. Domínguez and Francisco Javier Ponce from the Drawing Department of CICESE for preparing the figures; Asael G. Arroyo Re for the English reviews of the manuscript.

\section{REFERENCES}

[1] Kriegstein, A.R., Castellucci, V. and Kandel, E.R. (1974) Metamorphosis of Aplysia californica in laboratory culture. Proceedings of the National Academic of Science USA, 71, 3654-3658. doi:10.1073/pnas.71.9.3654

[2] Peretz, B. and Adkins, L. (1982) An index of age when birthdate is unknown in Aplysia californica: Shell size and growth in long-term maricultured animals. Biological Bulletin, 162, 333-344. doi:10.2307/1540987

[3] Capo, T.R., Fieber, L.A., Stommes, D.L. and Walsh, P.J. (2002) The effect of stocking density on growth rate and maturation time in laboratory-reared California sea hares. Journal of the American Association for Laboratory Animal Science, 41, 25-30.

[4] Fieber, L.A., Schmale, M.C., Jordi, N., Orbesen, E., Díaz, G. and Capo. T.R. (2005) Von Bertalanffy growth models for hatchery-reared Aplysia californica. Bulletin of Marine Science, 76, 95-104.

[5] Stommes, D., Lynne, B., Fieber, A., Beno, C., Gerdes, R. and Capo T.R. (2005) Temperature effects on growth, maturation, and lifespan of the California sea hare (Aplysia californica). Journal of the American Association for Laboratory Animal Science, 44, 31-35. 
[6] Kupfermann, I. and Carew, T.J. (1974) Behaviour patterns of Aplysia californica in its natural habitat. Behavioral Biology, 12, 317-337. doi:10.1016/S0091-6773(74)91503-X

[7] Sánchez-Ortiz, C.A. (2000) Biodiversidad de moluscos opistobranquios (Mollusca: Opisthobranchiata), del Pacífico mexicano: Isla Cedros-Vizcaíno e islas del Golfo de California parte Sur. Universidad Autónoma de Baja California Sur. Informe Final SNIB-CONABIO Proyecto No.L136, México City.

[8] Cruz, M., Hill, D. and Cortez, P. (2007) Biología y distribución de la Familia Aplysiidae (Babosas de mar) en la zona intermareal del Ecuador desde el 2003 al 2005. Acta Oceanográfica del Pacifico, 14, 155-161.

[9] Capo, T.R., Fieber, L.A., Stommes, D.L. and Walsh, P.J. (2003) Reproductive output in the hatchery-reared California sea hare at different stocking densities. Journal of the American Association for Laboratory Animal Science, 42, 31-35.

[10] Kandel, P. and Capo, T.R. (1979) The packaging of ova in the egg cases of Aplysia californica. The Veliger, 22, 194198.

[11] Fieber, L.A. (2000) The development of excitatory capability in Aplysia californica bag cells observed in cohorts. Developmental Brain Research, 122, 47-58. doi:10.1016/S0165-3806(00)00053-5

[12] Kelsh, S.W. and Neill, W.H. (1990) Temperature preference versus acclimation in fishes: Selection for changing metabolic optima. Transactions of the American Fisheries Society, 119, 601-610. doi:10.1577/1548-8659(1990)119<0601:TPVAIF $>2.3 . \mathrm{CO}$ $\underline{2}$

[13] Huey, R.B. (2003) Behavioral drive versus behavioral inertia in evolution: A null model approach. The American Naturalist, 161, 357-366. doi:10.1086/346135

[14] Huey, R.B. (1991) Physiological consequences of habitat of habitat selection. The American Naturalist, 137, S91S115. doi:10.1086/285141

[15] Tepler, S, Mach, K. and Denny, M. (2011) Preference versus performance: Body temperature of the intertidal snail Chlorostoma funebralis. Biological Bulletin, 220, 107-117.

[16] Reynolds, W.W., Casterlin, M.E. and Millington, S.T. (1978) Circadian rhythm of preferred temperatures in the bowfish Amia calva, a primitive holostean fish. Comparative Biochemistry and Physiology, 60A, 107-109. doi:10.1016/0300-9629(78)90044-0

[17] Fry, F.E. (1947) Effects of the environment on animal activity. Ontario Fisheries Research Laboratory Publication, Biol. Ser. 55, 68, 1-62.

[18] Reynolds, W.W. and Casterlin, M.E. (1979) Behavioral thermoregulation and the "final preferendum" paradigm. American Zoologist, 19, 211-224.

[19] Jobling, M. (1981) Temperature tolerance and the final preferendum-rapid methods for the assessment of optimum temperatures. Journal of Fish Biology, 19, 439-455. doi:10.1111/j.1095-8649.1981.tb05847.x

[20] Luttterschmidt, W.I. and Hutchison, V.M. (1997) The criti- cal thermal maximum: Data to support the onset of spasms the definitive end point. Canadian Journal of Zoologist, 75, 1553-1560.

[21] Dallas, H.F. and River-Moore, N.A. (2012) Critical thermal maxima of aquatic macroinvertebrates: Toward identifying bioindicators of thermal alteration. Hydrobiologia, 679, 61-76. doi:10.1007/s10750-011-0856-4

[22] Cox, D.K. (1974) Effects of the three heating rates on the critical thermal maximum of bluegill. In: Gibbons, J.W. and Sharitz, R.R., Eds., Thermal Ecology, AEC Symposium Series (Conf-73055), Springfield, 150-163.

[23] Dallas, H.F. and Ketley, Z.A. (2011) Upper thermal limits of aquatic macroinvertebrates: Comparing critical thermal maxima with 96- $\mathrm{LT}_{50}$ values. Journal of Thermal Biology, 36, 322-327. doi:10.1016/j.jtherbio.2011.06.001

[24] Dong, Y., Yu, S., Wang, Q. and Dong, S. (2011) Physiological responses in a variable environment: Relationship between metabolism. Hsp and thermotolerance in an intertidal-subtidal species. Plos One, 6, e26446. doi: $10.1371 /$ journal.pone.0026446

[25] Lemos, D., Phan, V.N. and Alvarez, G. (2001) Growth, oxygen consumption, amomonia- $\mathrm{N}$ excretion, biochemical composition and energy content of Farfantepenaeus paulensis Perez-Farfante (Crustacea, Decapoda, Penaeidae) early postlarvae in different salinities. Journal of Experimental Marine Biology and Ecology, 261, 55-74. doi:10.1016/S0022-0981(01)00260-X

[26] Altinok, I. and Grizzle, J.M. (2003) Effects of low salinities on oxygen consumption of selected euryhaline and stenohaline freshwater fish. Journal of the World Aquaculture Society, 34, 113-117. doi:10.1111/j.1749-7345.2003.tb00046.x

[27] Brougher, D.S., Douglass, L.W. and Soares, J.H. (2005) Comparative oxygen consumption and metabolism of striped bass Morone saxatilis and its hybrid M. chrysops o $\times$ M. saxatilis $\widehat{D}$. Journal of the World Aquaculture Society, 36, 521-529. doi:10.1111/j.1749-7345.2005.tb00400.x

[28] Salvato, B., Coumo, V., Di Muro, P. and Beltramini, M. (2001) Effect of environmental parameters on the oxygen consumption of marine invertebrates: A comparative factorial study. Marine Biology, 138, 659-668. doi:10.1007/s002270000501

[29] Das, T., Pal, A.K., Chakraborty, S.K., Manush, S.M., Chatterjee, N. and Mukherjee, S.C. (2005) Thermal tolerance and oxygen consumption of Indian major carps acclimated to four temperatures. Journal of Thermal Biology, 29, 157-163. doi:10.1016/j.jtherbio.2004.02.001

[30] Díaz, F., Re, A.D., Medina, Z., Re, G., Valdez, G. and Valenzuela, F. (2006) Thermal preference and tolerance of green abalone Haliotis fulgens (Philippi, 1845) and pink abalone Haliotis corrugata (Gray, 1828). Aquaculture Research, 37, 877-884. doi:10.1111/j.1365-2109.2006.01506.x

[31] Nelson, S.G., Simmons, M.A. and Knight, A.W. (1985) Calorigenic effect of diet on the grass shrimp Crangon franciscorum (Crustacea: Crangonidae). Comparative Biochemistry and Physiology, 82A, 373-376. doi:10.1016/0300-9629(85)90870-9 
[32] Beamish, F.W.H. and Trippel, E.A. (1990) Heat increment: A static or dynamic dimension in bioenergetic models? Transactions of the American Fisheries Society, 119, 649661.

doi:10.1577/1548-8659(1990)119<0649:HIASOD $>2.3 . \mathrm{C}$ $\underline{\mathrm{O} ; 2}$

[33] Zar, J.H. (1999) Biostatiscal analysis. Prentice Hall, Upper Saddle River, 645.

[34] Tukey, J.W. (1977) Exploratory data analysis. AdissonWesley, Reading, 688.

[35] Díaz, F., Del Rio-Portilla, M., Sierra, E., Aguilar, M. and Re-Araujo, A. (2000) Preferred temperature and critical thermal maxima of red abalone Haliotis rufescens. Journal of Thermal Biology, 25, 257-261. doi:10.1016/S0306-4565(99)00032-7

[36] Díaz, F., Salas A., Re, A.D., Gonzalez, M. and Reyes, I. (2011) Thermal preference and tolerance of Megastrea (Lithopoma) undosa (Wood, 1828; Gastropoda: Turbinidae). Journal of Thermal Biology, 36, 34-37. doi:10.1016/j.jtherbio.2010.10.004

[37] Stern, S., Borut, A. and Cohen, D. (1984) The effect of salinity and ion composition on oxygen consumption and nitrogen excretion of Macrobrachium rosenbergii. Comparative Biochemistry and Physiology, 79A, 271-274. doi:10.1016/0300-9629(84)90428-6

[38] Cerezo-Valverde, J. and García-García, B. (2004) Influence of body weight and temperature on post-prandial oxygen consumption of common octopus (Octopus vulgaris). Aquaculture, 233, 599-613. doi:10.1016/j.aquaculture.2003.11.025

[39] Zheng, Z., Jin, C., Li, M., Bai, P. and Dong, S. (2008) Effects of temperature and salinity on oxygen consumption and ammonia excretion of juvenile miiuy croaker, Miichthys miiuy (Basilewsky). Aquaculture International, 16, 581-589. doi:10.1007/s10499-008-9169-7

[40] Kavaliers, M. (1980) A circadian rhythm of behavioral thermoregulation in a freshwater gastropod, Helisoma trivolis. Canadian Journal of Zoology, 58, 2152-2155. doi:10.1139/z80-295

[41] Taylor, R.C. (1984) Thermal preference and temporal distribution in three crayfish species. Comparative Biochemistry and Physiology, 77A, 513-517.

\section{doi:10.1016/0300-9629(84)90220-2}

[42] Bückle, R.L.F., Díaz-Herrera, F. Correa-Sandoval, F. BarónSevilla, B. and Hernandez-Rodríguez, M. (1994) Diel thermoregulation of the crawfish Procambarus clarkii (Crustacea, Cambaridae). Journal of Thermal Biology, 19, 419-422. doi:10.1016/0306-4565(94)90041-8

[43] Brett, J.R. (1971) Energetic responses of salmon to temperature. A study of some thermal relations in the physicology and freshwater ecology of sockeye salmon Orcorhynchus nerka. American Zoologist, 11, 99-113.

[44] Fraenkel, G.S. and Gunn, D.L. (1961) The orientation of animals, kineses, taxes and compass reactions. Dover Publications, New York, 376.

[45] Smith, A.M. (1991) The role of suction in the adhesion of limpets. Journal of Experimental Biology, 161, 151-169.

[46] Morley, S.A., Lemmon, V., Obermüller, B.E., Spicer, J.I., Clark, M.S. and Peck, L.S. (2011) Duration tenacity: A method for assessing acclimatory capacity of the Antarctic limpet Nacella concinna. Journal of the Experimental Marine Biology and Ecology, 399, 39-42. doi:10.1016/j.jembe.2011.01.013

[47] Davenport, J. (1997) Comparison of the biology of the intertidal sub Antartic limpets Nacella concinna and Kerguelenella lateralis. Journal of Molluscan Studies, 63, 39-48. doi:10.1093/mollus/63.1.39

[48] Flammang, P., Ribesse, R. and Jangoux, M. (2002) Biomechanics of adhesion in sea cucumber cuverian tubules (Echinodermata, Holothuroidea). Integrative Comparative Biology, 42, 1107-1115. doi:10.1093/icb/42.6.1107

[49] Santos, R. and Flammang, P. (2007) Intra-and interspecific variations of attachment strength in sea urchins. $M a-$ rine Ecology Progress Series, 332, 129-142. doi: $10.3354 / \mathrm{meps} 332129$

[50] Miller, N.A., Paganini, A.W. and Stillman, J.H. (2013) Differential thermal tolerance and energetic trajectories during ontogeny in porcelain crabs, genus Petrolisthes. Journal of Thermal Biology, 38, 79-85. doi:10.1016/j.jtherbio.2012.11.005 